\title{
36 Responses on Invasive Species
}

\section{Montserrat Vilà}

$\mathrm{H}$ umans have introduced species to areas where they could not disperse naturally. Some of these nonnative (also termed alien or exotic) species successfully spread in the wild, becoming invasive species. Biological invasions, omnipresent around the world, affect biodiversity, ecosystem services, and human well-being. Well-known examples include killer alga (Caulerpa taxifolia), cane toad (Rhinella marina), cheatgrass (Bromus tectorum), golden apple snail (Pomacea canaliculata), tiger mosquito (Aedes albopictus), and muskrat (Ondatra zibethicus).

Invasive Species: What Everyone Needs to Know addresses 36 interdisciplinary questions on biological invasions. Ecologist Daniel Simberloff (University of Tennessee) enriches his responses with more than 500 examples from a broad array of taxa, ecosystem types, and geographic regions. He notes the major progress achieved since the early 1990s, when the Rio Convention on Biological Diversity included the goal to "prevent the introduction of, control or eradicate those alien species which threaten ecosystems, habitats or species."

Nonnative species arrive via diverse pathways. Some are deliberately released into the wild-for example, for sport hunting or fishing, to feed live-

Invasive Species

What Everyone Needs to Know

by Daniel Simberloff

Oxford University Press,

New York, 2013. 345 pp. \$74

f47.99. ISBN 9780199922017.

Paper, \$16.95., £10.99.

ISBN 9780199922031 stock, and even for conservation

and restoration purposes (such as "enriching" the biota of degraded lands). Pets and many ornamental plants escape from homes and yards. Invasive species may be introduced unintentionally in ballast water, as hitchhikers on other nonnatives, or in commodities. Increased travel and trade, high demand for new commodities, construction of major infrastructures, and opening of new commercial routes challenge the control of nonnative species' entrances and exacerbate their impacts. Interactions among two or more invasives can intensify their impacts on native species, communities, and ecosystems, producing what Simberloff terms an "invasional meltdown."

The reviewer is at the Estación Biológica de Doñana (EBDCSIC), 41092 Sevilla, Spain. E-mail: montse.vila@ebd.csic.es of thermodynamics but simply statements of patterns that are more or less dominant, although there are always exceptions."

Research on biological invasions has also greatly increased our understanding of species evolution and ecology at all levels of ecological complexity $(1,2)$. This is a major reason why scientists are attracted to the topic. In fact, biological invasions provide giant experiments for addressing questions such as the mechanisms of fast evolution, the persistence of small populations, the rules of species assemblages, and the effects of a single species on ecosystem functioning. Simberloff's account shows that research on biological invasions is well integrated into mainstream ecology or evolutionary biology.

In the realm of applications, the book provides compelling information for improving conservation of native species and ecosystems threatened by invasive species. Management of biological invasions basically comprises prevention, early detection, and eradication. Simberloff devotes a third of the book to aspects of effective management of invasive species. He describes not only technological improvements but also policy options, cultural perceptions, citizen-science initiatives, and controversies surrounding biological invasions.

"In a policy and management context, it makes little sense to consider all introduced species or even all invasive introduced species in the aggregate." Thus, we need to provide managers risk assessment tools for modeling the potential distribution of nonnative species and protocols for scoring species based on their likelihood of invading and disrupting. Despite rapid dvances, much work still needs to be done, especially on screening the risks of accidental introductions. This requires a thorough exploration of the links among pathways of introduction, invasion success, and impact (3). Undoubtedly, these analyses must integrate biology with socioeconomic information such as trading trends.

As many researchers realize (4), the management of nonnative species can generate considerable controversy. Major disputes arise from judgments that some actions against introduced species are xenophobic, some introduced species are beneficial, and efforts to control some invasives are futile. Noting positions of conservationists, philosophers, lawyers, and even politicians, Simberloff discusses these controversies in depth.

Written for nonexpert but educated readers, Invasive Species will reward those who demand well-documented information without requiring the scientific details. By extending his wide-ranging survey of biological invasions beyond their biology, Simberloff acknowledges the crucial human dimensions of invasive species (5).

References

1. R. M. Callaway, ]. L. Maron, Trends Ecol. Evol. 21, 369 (2006).

2. D. F. Sax et al., Trends Ecol. Evol. 22, 465 (2007)

3. B. Leung et al., Ecol. Lett. 15, 1475 (2012).

4. D. Simberloff et al., Trends Ecol. Evol. 28, 58 (2012).

5. J. A. McNeely, Ed., The Great Reshuffling: Human Dimensions of Alien Species (IUCN, Cambridge, 2001); http:// data.iucn.org/dbtw-wpd/edocs/2001-002.pdf.

10.1126/science. 1245174 